Article

\title{
Mechanistic insight into the attenuation of initial pilocarpine- induced seizures in young rats by a non-convulsive MSO dose
}

\author{
Marek J. Pawlik ${ }^{1, *}$ ORCID ID: 0000-0002-9060-7230, Blanca I. Aldana ${ }^{2}$ ORCID ID: 0000-0002-5027-1218, Lautaro F. \\ Belfiori-Carrasco ${ }^{2}$ ORCID ID: 0000-0003-1930-1332, Marta Obara-Michlewska ${ }^{1}$ ORCID ID: 0000-0003-3659-1335, \\ Mariusz P. Popek ${ }^{1}$ ORCID ID: 0000-0003-4394-3394, Anna Maria Czarnecka ${ }^{1}$ ORCID ID: 0000-0003-4235-2963, Jan \\ Albrecht ${ }^{1, *}$ ORCID ID: 0000-0001-6063-6228
}
1 Department of Neurotoxicology, Mossakowski Medical Research Institute, Polish Academy of Sciences, Warsaw, Poland; mobara@imdik.pan.pl (M.O.-M.); mpopek@imdik.pan.pl (M.P.P.); aczarnecka@im- dik.pan.pl (A.M.C.)
2 Department of Drug Design and Pharmacology, Faculty of Health and Medical Sciences, University of Co- penhagen, Denmark; blanca.aldana@sund.ku.dk (B.I.A); vch443@ku.dk (L.F.B.-C.)
* Correspondence: jalbrecht@imdik.pan.pl (J.A); mpawlik@imdik.pan.pl (M.J.P.); Tel.: +48-22-6086-617 (J.A.); +48-22-6086-441 (M.J.P.)

\begin{abstract}
Pretreatment with non-convulsive dose of methionine sulfoximine (MSO) attenuated lithium-pilocarpine-induced (Li-Pilo) seizures in young rats [1]. We hypothesized that the effect of MSO results from a) glutamine synthetase block-mediated inhibition of conversion of Glu/Gln precursors to neurotransmitter Glu, and/or from b) altered synaptic Glu release. Pilo was administered $60 \mathrm{~min}$ prior to sacrifice, $\mathrm{MSO}$ at $75 \mathrm{mg} / \mathrm{kg}$, i.p., $2.5 \mathrm{~h}$ earlier. $\left[1,2-{ }^{13} \mathrm{C}\right]$ acetate and $\left[\mathrm{U}-{ }^{13} \mathrm{C}\right]$ glucose were i.p.injected either together with Pilo (onset) or $15 \mathrm{~min}$ before sacrifice (final phase). Their conversion to Glu and Gln in hippocampus and entorhinal cortex was followed using $\left[{ }^{13} \mathrm{C}\right]$ gas chromatographymass spectrometry. Release of in vitro loaded $\left[{ }^{3} \mathrm{H}\right] \mathrm{D}-\mathrm{Asp}$ from ex vivo brain slices was measured in continuously collected superfusates. Protein and mRNA expression were measured by Western Blot and real-time PCR techniques, respectively. At no time point nor brain region did MSO modify incorporation of $\left[{ }^{13} \mathrm{C}\right]$ to Glu or Gln in Pilo-treated rats. MSO pretreatment decreased by $\sim 37 \%$ high potassium-induced $\left[{ }^{3} \mathrm{H}\right] \mathrm{D}$-Asp release and reduced by $\sim 50 \%$ the synaptic vesicular Glu transporter VGLUT1 protein, but not mRNA content in the hippocampus. The results indicate that MSO at nonconvulsive dose mitigates the initial Pilo-induced seizures by interfering with synaptic Glu-release but not with neurotransmitter Glu recycling.
\end{abstract}

Keywords: epilepsy; glutamatergic transmission; glutamine synthesis; methionine sulfoximine; metabolomics

\section{Introduction}

In mammalian brain, glutamine synthetase (GS) is bimodaly involved in the regulation of excitatory, glutamatergic transmission [2,3]. On one hand, GS-mediated conversion of Glu and ammonia to Gln in astrocytes neutralizes Glu newly released from neurons. On the other hand, a portion of Gln newly formed in astrocytes is transferred back to neurons by specific Gln transporters catalyzing its astrocytic release (system $\mathrm{N}$ ) and neuronal uptake (system A), respectively [4-6]. Here it enriches neurotransmitter pool of Glu: the above sequence of events are defined as the glutamine-glutamate cycle (GGC).

Methionine sulfoximine (MSO) is an irreversible GS inhibitor [7]. Instant GS inhibition by high MSO doses rapidly stimulates glutamatergic transmission, inducing convulsions and seizures [7-9], while GS inactivation associated with prolonged MSO treatment is accompanied by hippocampal sclerosis and spontaneous recurrent seizures (SRS) resulting from inefficient Glu uptake, a status manifesting chronic temporal lobe epilepsy (TLE) $[8,10-12]$. GS loss in brain-vulnerable regions (mainly hippocampus) has also been 
found to correlate with advanced TLE induced by other chemical stimuli, including pilocarpine (Pilo) [13-15] or kainic acid (KA) [16].

On the other hand, exogenously added Gln will induce a long-lasting, glutamatergic transmission-bolstering effect. This has been directly demonstrated in striatal cortical slices [17], but has also been recorded in epilepsy models: in entorhinal cortical slices derived from Pilo-treated chronic epileptic rats [18], in rats with KA-induced seizures [19], and in an in vitro model of post-traumatic epilepsy [20]. The role of Gln in promoting excitatory transmission and seizures has also been demonstrated in experiments employing low MSO doses causing moderate inhibition of GS. Low MSO depressed glutamatergic transmission and epileptiform discharges in cerebral cortical slices in vitro [21,22]. In vivo, intracerebral administration of MSO reduced amygdala kindling- induced seizures [23].

We recently have demonstrated that in 24-day rats treated with lithium-pilocarpine (Li-Pilo), pretreatment with MSO at a low dose which produced no convulsions, delayed the onset of, and attenuated the initial convulsive and electrographic seizures [1]. It appeared reasonable to speculate that MSO at this low dose inhibited an aspect of glutamatergic transmission critical for provoking the initial seizures. In this study we tested two not mutually exclusive hypotheses regarding the mechanism by which MSO could induce the inhibition. The first was that, MSO interferes with the GGC in a way affecting de novo Glu synthesis in this model. To test this hypothesis, $\left[{ }^{13} \mathrm{C}\right]$ mass spectrometry was employed to follow incorporation in vivo of ${ }^{13} \mathrm{C}$ labelled metabolic precursors: acetate and glucose, to Glu and Gln. This procedure has previously been used to study Glu synthesis and metabolism in models of brain pathologies associated with enhanced glutamatergic transmission [24-30], including treatments with convulsive MSO dose in vivo [24] and in vitro [30-32]. The main labelling patterns of the metabolites from [U-13C]glucose or [1,2$\left.{ }^{13} \mathrm{C}\right]$ acetate in the experimental setting of the present investigation are detailed in Scheme 1.

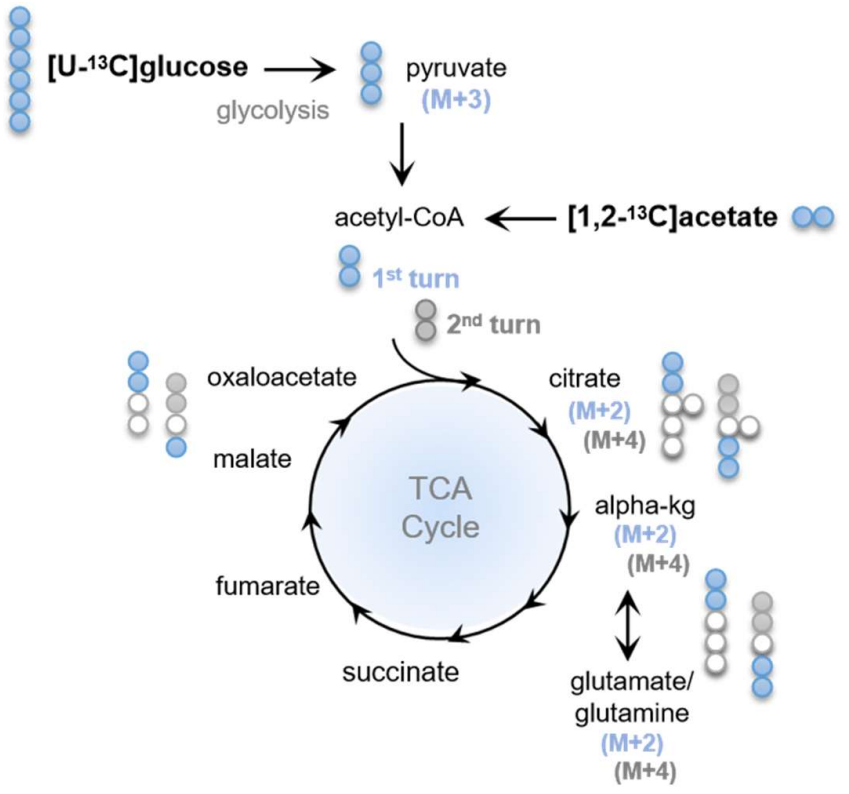

Scheme 1. Schematic representation of the main labelling patterns obtained after incubation with $\left[\mathrm{U}-{ }^{13} \mathrm{C}\right] \mathrm{glucose}$ or $[1,2$ ${ }^{13} \mathrm{C}$ ]acetate. $\left[\mathrm{U}-{ }^{13} \mathrm{C}\right]$ glucose is taken up by cells in the brain tissue and metabolized to $\left[\mathrm{U}-{ }^{13} \mathrm{C}\right]$ pyruvate $(\mathrm{M}+3)$ during glycolysis. [U-13 $\mathrm{C}$ ]pyruvate which in turn can be metabolized in the tricarboxylic acid (TCA) cycle, entering as $\left[1,2-{ }^{13} \mathrm{C}\right] \mathrm{Ace}-$ tyl-Coenzyme A $\left(\left[1,2-{ }^{13} \mathrm{C}\right] \mathrm{Ac}-\mathrm{CoA}\right)$ which reacts with unlabelled oxaloacetate and, hence, double-labelled (M+2) TCA cycle intermediates are produced, illustrated as blue circles. $\left[1,2-{ }^{13} \mathrm{C}\right]$ acetate can also enter the TCA cycle via $\left[1,2-{ }^{13} \mathrm{C}\right] \mathrm{Ac}-$ $\mathrm{CoA}$ and generate double-labelled intermediates. The labelled neuroactive amino acid $\left[4,5-{ }^{13} \mathrm{C}\right] \mathrm{glutamate}(\mathrm{M}+2) \mathrm{can}$ be 
formed from $\alpha\left[4,5-{ }^{13} \mathrm{C}\right]$ ketoglutarate $(\alpha-\mathrm{kg} \mathrm{M}+2)$. From glutamate $(\mathrm{M}+2),\left[4,5-{ }^{13} \mathrm{C}\right]$ glutamine $(\mathrm{M}+2)$ can be synthesized in the astrocytes by glutamine synthase (GS). In the second turn of the TCA cycle, $\left[1,2-{ }^{13} \mathrm{C}\right] \mathrm{Ac}-\mathrm{CoA}$ reacts with oxaloacetate $\mathrm{M}+2$ formed in the first turn of the cycle, resulting in the production of $\mathrm{M}+3$ and $\mathrm{M}+4$ labelled metabolites (depicted with grey circles).

The second hypothesis was that MSO interferes with the availability of Glu at the synapse by modifying its release and/or reuptake. Here we took into consideration earlier published data demonstrating that MSO affects Glu transport in various brain preparations in vivo [33] and in vitro [34,35]. To account for this hypothesis, we tested the effect of MSO on the uptake and release of the newly taken up ${ }^{3} \mathrm{H}$-labelled Glu surrogate, D-aspartate $\left(\left[{ }^{3} \mathrm{H}\right] \mathrm{D}-\mathrm{Asp}\right)$ in ex vivo brain slices derived from rats treated with a low dose of MSO. High, depolarizing potassium concentrations were used as a generic release stimulus. Having found that MSO in the present setting inhibits [ $\left.{ }^{3} \mathrm{H}\right] \mathrm{D}-\mathrm{Asp}$ release, we begun a search into the mechanism by which MSO interferes with the mechanism of Glu release. Towards this end we measured the expression of VGLUT1, the principal vesicular Glu transporter responsible for loading synaptic vesicles with glutamate [36].

\section{Results}

\subsection{Generation of Glu and $\mathrm{Gln}$ from $\left[U-{ }^{13} \mathrm{C}\right]$ glucose or $\left[1,2-{ }^{13} \mathrm{C}\right]$ acetate}

\subsubsection{Glutamate}

At 15 minutes after Pilo administration ${ }^{13} \mathrm{C}$-enrichment of Glu from labelled glucose was drastically decreased by MSO both after the first $(\mathrm{M}+2)$ and the second turnover $(\mathrm{M}+4)$ (Figure 1. A.). In the latter, the levels of 5 out of 6 samples were below the detection limit of GC-MS. However, Pilo treatment alone did not induce changes in the enrichment (Pilo group), MSO failed to decrease the ${ }^{13} \mathrm{C}$-enrichment from glucose in Pilo-treated rats (MSO+Pilo group). No changes after either combination of treatments were apparent in the entorhinal cortex, except for a statistically insignificant tendency towards increase of $\mathrm{M}+4$ labeling in Glu (Figure 1. C.). A slight tendency to decrease of Glu labelling from acetate by MSO became apparent in the entorhinal cortex (Figure 1. D.) but not in the hippocampus (Figure 1. B.). Again, MSO failed to decrease the ${ }^{13} \mathrm{C}$-enrichment from acetate, leaving $\mathrm{M}+2$ and $\mathrm{M}+4$ Glu levels unchanged relative to the control in both brain structures. No noteworthy changes in Glu ${ }^{13} \mathrm{C}$ enrichment were observed at $60 \mathrm{~min}$ after Pilo administration (Figure 1. E.-H.). In both time points and brain structures, and under either condition, ${ }^{13} \mathrm{C}$-enrichment in Glu derived from labeled glucose was around two times higher than that derived from acetate. 


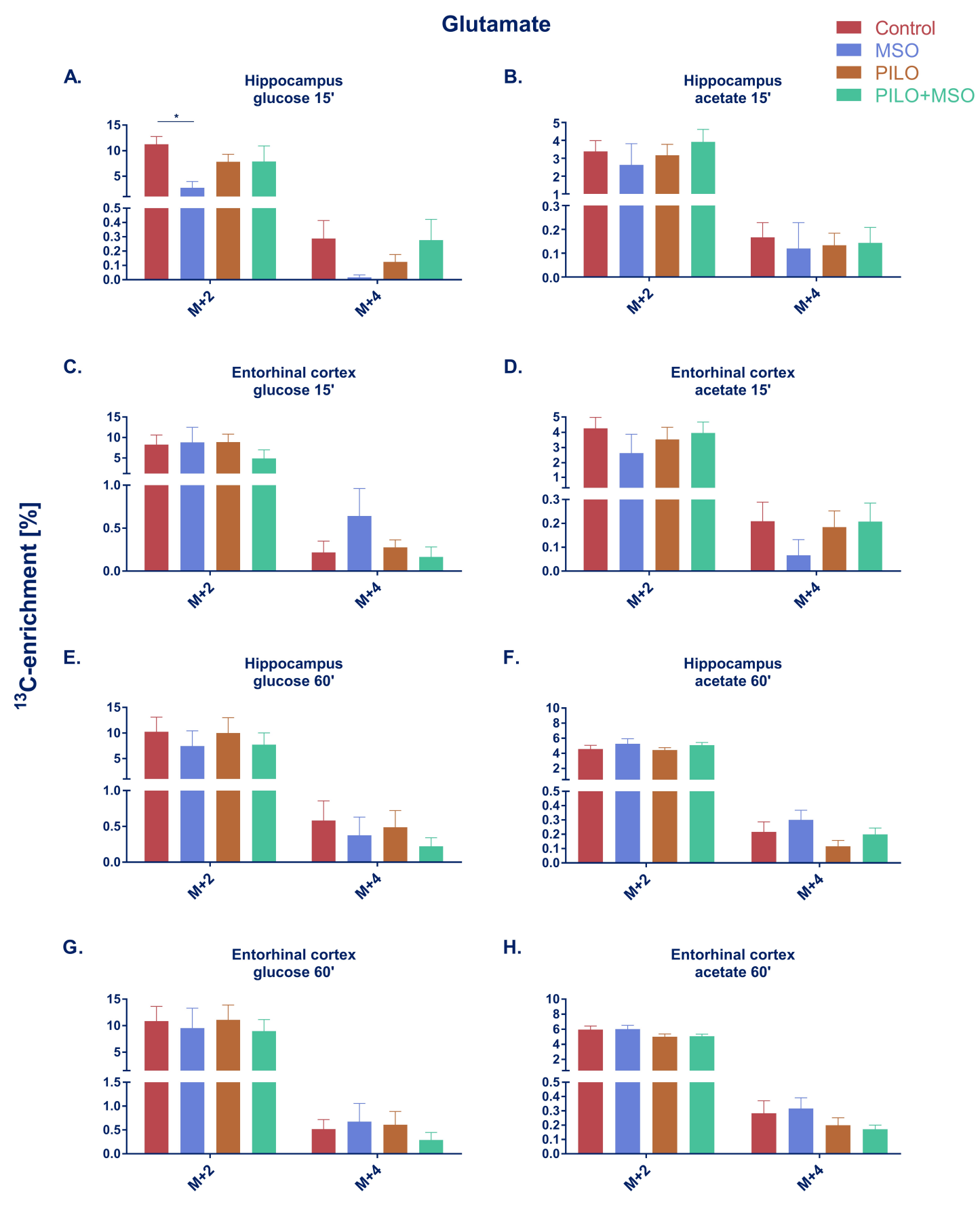

Figure 1. Percentage of ${ }^{13} \mathrm{C}$-enrichment in glutamate derived from $\left[\mathrm{U}-{ }^{13} \mathrm{C}\right]$ glucose or $\left[1,2-{ }^{13} \mathrm{C}\right]$ acetate in hippocampus and entorhinal cortex of TLE model rats. * $\mathrm{p}<0.05$, one-way ANOVA with Tukey's correction; Control, MSO, Pilo, MSO+Pilo N = 6; mean \pm SEM. Designations "15" and "60" refer to the onset and final phase of Pilo action and correspond to 150-165 min or 195-210 min time of action of MSO, respectively, rendering in each case a 15 min presence of the isotope in the body.

\subsubsection{Glutamine}

Similarly to glutamate, glutamine enrichment from ${ }^{13} \mathrm{C}$-labelled glucose in hippocampus at 15 minutes was significantly reduced by MSO after the first turnover and almost indeterminable after the second turnover (4 out of 6 samples below detection limit) (Figure 2. A.). At $15 \mathrm{~min}, \mathrm{MSO}$ failed to significantly affect glutamine enrichment from glucose in the entorhinal cortex (Figure 2. C.). A slight tendency towards decrease of Gln labelling 
by MSO was observed in both structures at 60 minutes when glucose was used as a precursor (Figure 2. E., G.). At $15 \mathrm{~min}$, a tendency of MSO to decrease Gln labelling was also observed in acetate-derived metabolites in both structures; however, the effect did not reach statistical significance in either of the groups (Fig. 2. B., D.). No change was observed in either structure after either treatment at 60 min (Fig. 2. F., H.). Unlike Glu, where majority of the newly labelled neurotransmitter originated from glucose, more than twice as much Gln was labelled from acetate than from glucose.

Glutamine Control

A.

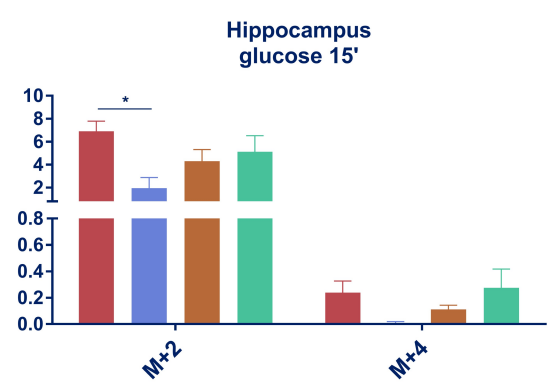

C.

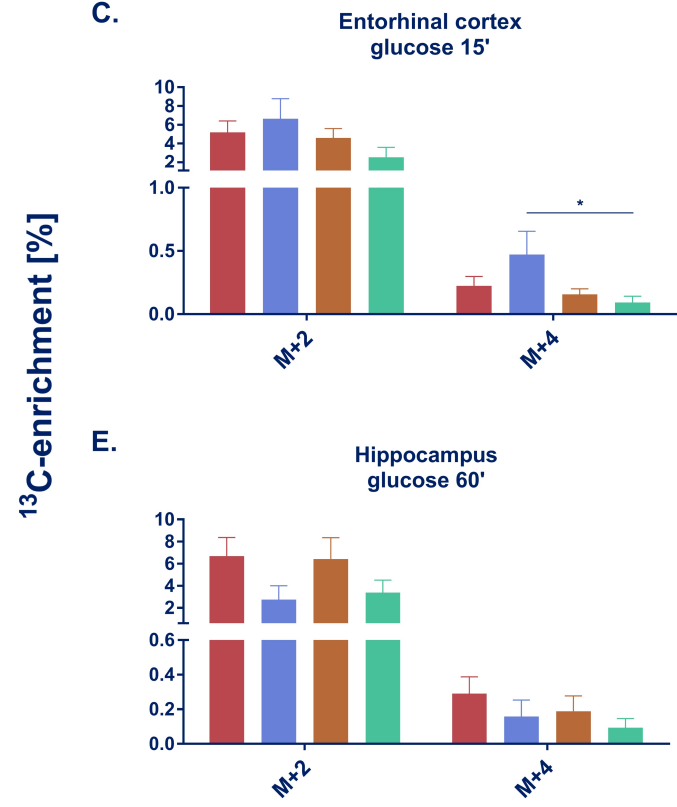

G.

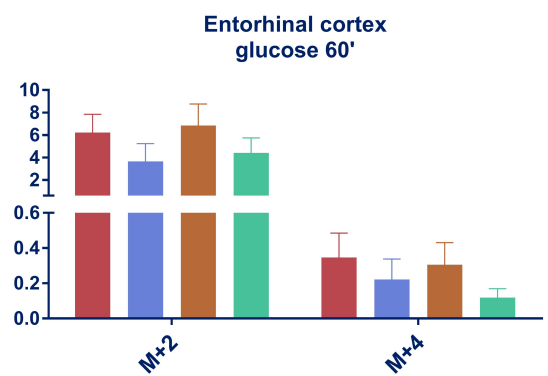

B.

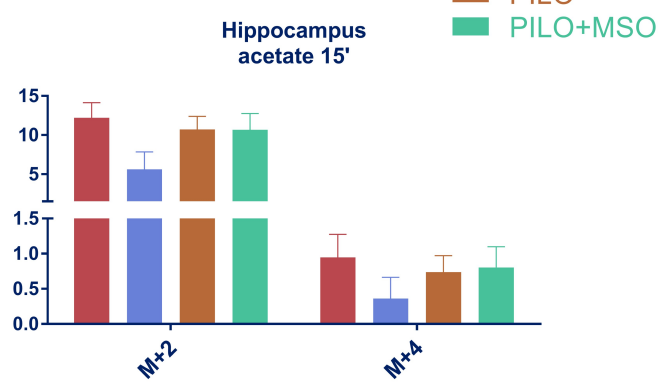

D.

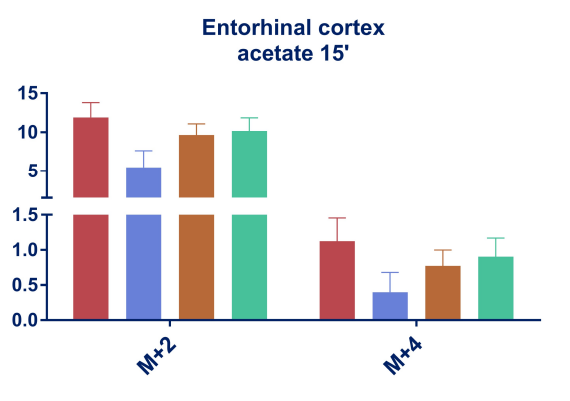

F.

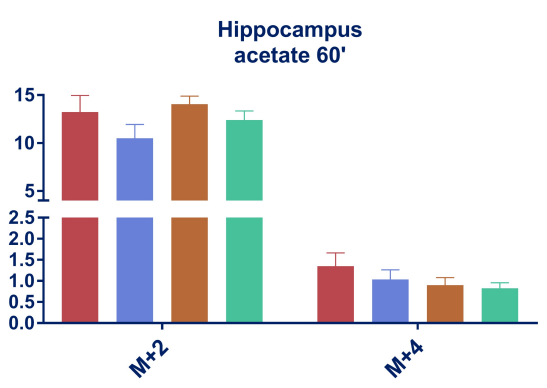

H.

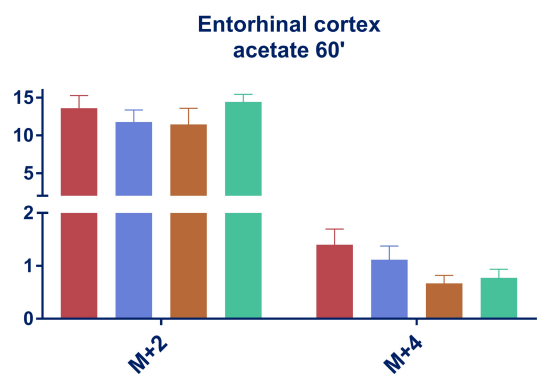

Figure 2. Percentage of ${ }^{13} \mathrm{C}$-enrichment in glutamine derived from $\left[\mathrm{U}-{ }^{13} \mathrm{C}\right]$ glucose or $\left[1,2-{ }^{13} \mathrm{C}\right]$ acetate in hippocampus and entorhinal cortex of TLE model rats. * - p < 0.05, one-way ANOVA with Tukey's correction; Control, MSO, Pilo, 
MSO+Pilo N = 6; mean \pm SEM. Designations "15"” and "60" spond to 150-165 min or 195-210 min time of action of MSO, respectively, rendering in each case a 15 min presence of the isotope in the body.

\subsection{Glu and Gln brain tissue content in MSO and/or Pilo-treated rats (HPLC study)}

None of the treatments produced statistically significant changes in hippocampal or entorhinal cortical Glu at either time point. Considering all the experimental variants, the Glu content ranged from $531.1 \pm 89.4$ in entorhinal cortex to $788.1 \pm 187.8$ in hippocampus (nmol/mg of protein, mean $\pm \mathrm{SD}$ ). This result is not surprising, as changes in rat brain Glu content have been reported to be refractory to a $6 \mathrm{~h}$ treatment with MSO doses 2 times higher than those used in the present study [37].

\section{3. $\left[{ }^{3} H\right] D-$ Asp efflux}

D-Asp release evoked by $\mathrm{K}^{+}$-induced depolarization was markedly lowered due to administration of MSO (Figure . A.). For four consecutive minutes after potassium pulse $\left[{ }^{3} \mathrm{H}\right] \mathrm{D}-\mathrm{Asp}$ levels in individual fractions were found to be significantly decreased in comparison with control. Area under the curve was on average $37 \%$ smaller in the MSO group as well ( $2.445 \pm 0.139$ vs. $3.888 \pm 0.239$ in control), indicating that the whole released pool of D-Asp was reduced. Baseline level of D-Asp was slightly decreased $(0.204 \pm 0.006 \%$ in MSO vs. $0.309 \pm 0.005 \%$ in control) which may suggest that D-Asp transport is affected by MSO in normal conditions as well, however, these changes were statistically insignificant.

A.

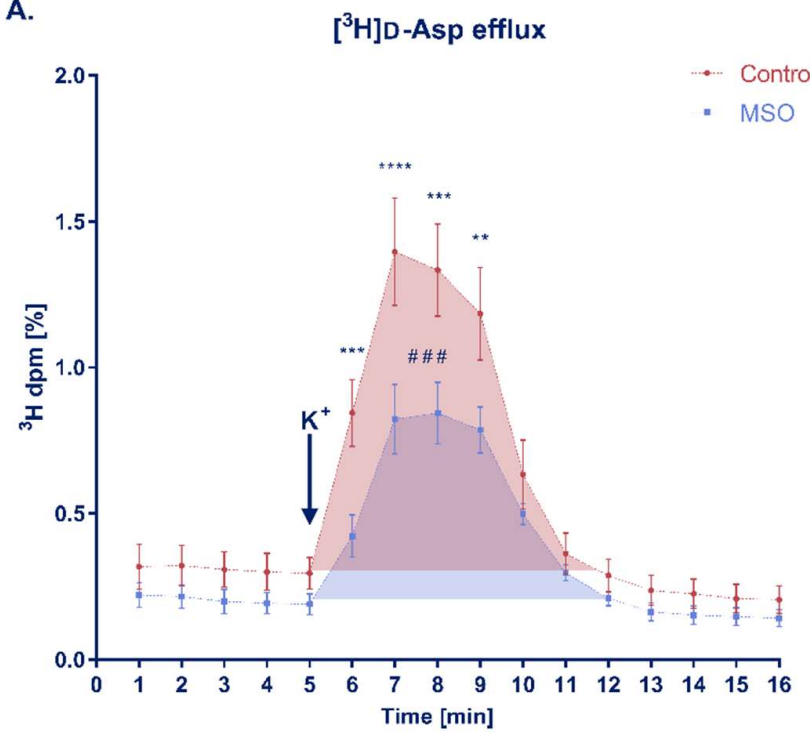

B.

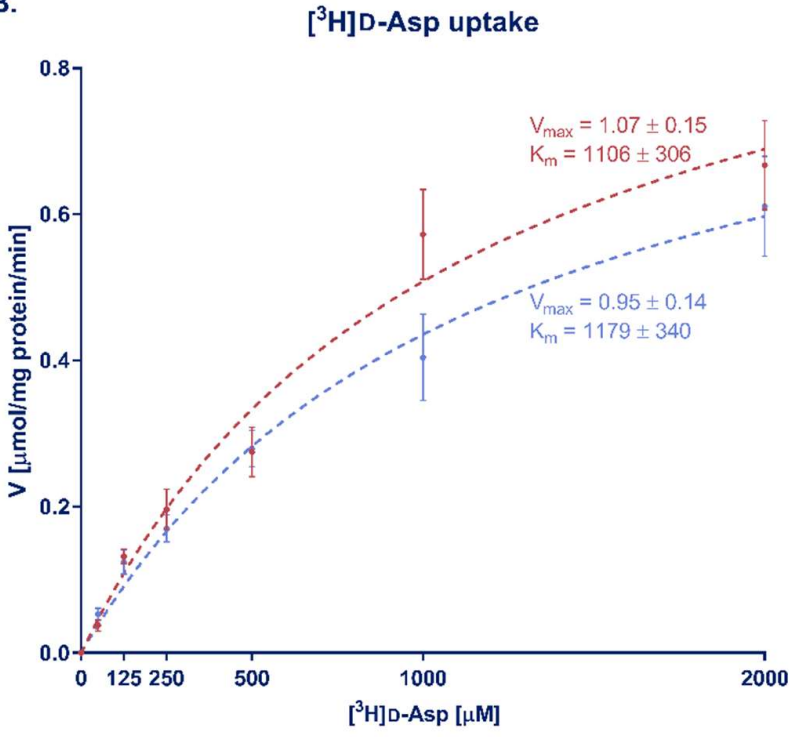

Figure 3. A. $\left[{ }^{3} \mathrm{H}\right] \mathrm{D}-\mathrm{Asp}$ efflux from brain slices of rats that received MSO or vehicle (control group). Arrow indicates the moment when $\mathrm{K}^{+}$depolarizing pulse was introduced. * - statistical significance between time points, multiple $\mathrm{t}$-test with Holm- Šidák correction; ${ }^{* *}, * *, * * * *-p<0.01,0.001,0.0001$ respectively; \# - statistical significance between areas under curve (AUC), one-tailed t-test; baseline for AUC comparison was set as a mean of fractions 1-5; baselines were compared using linear regression but changes between the slopes were not significant; control $\mathrm{N}=5, \mathrm{MSO} N=6$; $\operatorname{mean} \pm \mathrm{SEM}$. $\mathbf{B}$. $\left[{ }^{3} \mathrm{H}\right] \mathrm{D}$-Asp uptake from brain slices of rats that received MSO or vehicle (control group). The dashed lines represent Michaelis-Menten kinetic curves; $\mathrm{V}_{\max }$ and $\mathrm{K}_{\mathrm{m}}$ constants were compared using t-test; control, MSO N = 7; mean $\pm \mathrm{SEM}$.

\section{4. $\left[{ }^{3} H\right] D-$ Asp uptake}

There was no change in kinetics of [ $\left.{ }^{3} \mathrm{H}\right] \mathrm{D}-\mathrm{Asp}$ uptake, especially at lower concentrations of D-Asp $(50-500 \mu \mathrm{M})$ (Fig. 3. B.). At higher concentrations $(1000-2000 \mu \mathrm{M})$ a slight decrease of the uptake rate was observed in the MSO-treated group, however, the impact of MSO was not pronounced enough to significantly change $V_{\max }$ or $\mathrm{K}_{\mathrm{m}}$ parameters. This 
lack of effect of MSO confirms an earlier observation of unchanged Glu uptake in MSOpretreated rat brain synaptosomes [34].

\subsection{VGluT1 expression}

The level of VGLUT1 protein in the hippocampus, 3.5 hours after MSO administration, was significantly decreased to $47.17 \%$ of the control (Figure .). VGLUT1 mRNA expression was not altered by MSO treatment (Figure .).

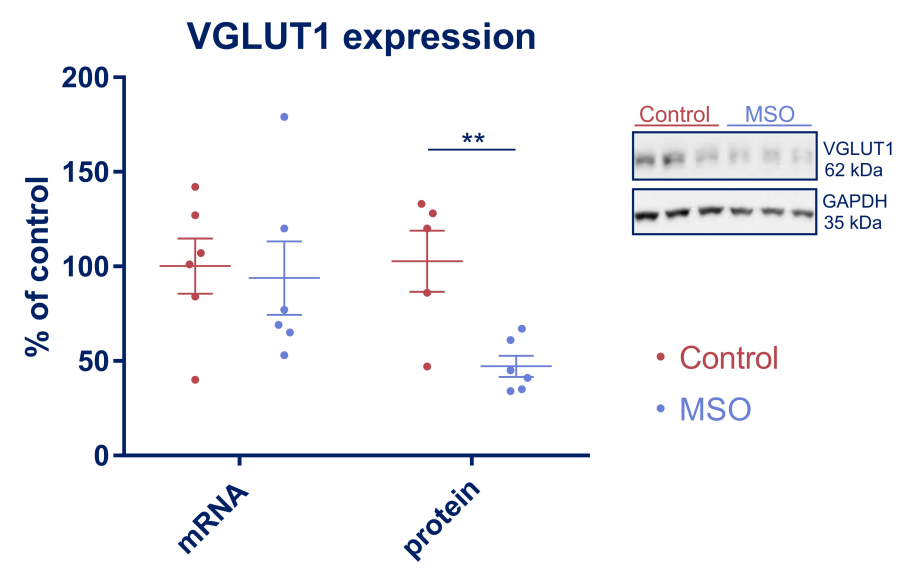

Figure 4. VGLUT1 mRNA and protein content with representative electrophorograms in the hippocampus of rats that received or not (control) MSO $3.5 \mathrm{~h}$ before decapitation. ${ }^{* *}$ - $\mathrm{p}<0.01$, t-test; mRNA: control, MSO N = 6; protein: control $\mathrm{N}=5, \mathrm{MSO} \mathrm{N}=6$; mean $\pm \mathrm{SEM}$.

\section{Discussion}

Our primary hypothesis regarding the mechanism by which low dose MSO attenuates the initial seizures in the Li-Pilo model was that MSO decreases the synthesis of neurotransmitter Glu by reducing the formation of its precursor Gln. The hypothesis was verified by measuring the effects of MSO treatment on the incorporation in vivo of ${ }^{13} \mathrm{C}$ labelled metabolic precursors: acetate and glucose to neurotransmitter Glu and Gln in hippocampus and entorhinal cortex, the two structures involved in the propagation of pilocarpineinduced seizures [38]. The only statistically significant change observed throughout the study was a decrease of ${ }^{13} \mathrm{C}$-enrichment of both Glu and Gln from glucose in hippocampus in the period of 150-165 min after MSO administration alone. However, at the very same time point, MSO failed to modulate in either direction the enrichment from glucose in rats with Li-Pilo-evoked seizures. Otherwise, MSO did not induce any significant effect on ${ }^{13} \mathrm{C}$-enrichment from glucose nor acetate, in any animal group either at the onset (15 $\mathrm{min})$ or at final stage $(60 \mathrm{~min})$ of the development of initial seizures. It is intriguing that the decrease by MSO of ${ }^{13} \mathrm{C}$-enrichment from glucose at $15 \mathrm{~min}$ was not observed at the later time point. Tentatively, this may be due to the biphasic effect of MSO on GS activity, leaving open the time brackets of the system in the final phase. A study with human GS revealed that initial competitive inhibition is a reversible process and is followed by irreversible activation [39]. The general absence of the effects of extrinsic factors became apparent notwithstanding the predictable metabolic fates of ${ }^{13} \mathrm{C}$ glucose or ${ }^{13} \mathrm{C}$ acetate in this experimental setting. Both preferential ${ }^{13} \mathrm{C}$-enrichment of Glu from glucose and of Gln from acetate are a good fit into the present views on the role of either of the compound as a metabolic precursor in neurons and astrocytes. Indeed, neurotransmitter pool of Glu is thought to be preferentially synthesized from glucose. The de novo synthesis may occur 
directly in neurons [40], or in astrocytes. The synthesis in astrocytes depends on anaplerosis, i.e. reactions providing a net increase in TCA cycle intermediates [41]. The primary anaplerotic enzyme in the brain, pyruvate carboxylase (PC), which serves as the main pathway of de novo glutamate synthesis is exclusively expressed in astrocytes [42,43]; reviewed by Schousboe et al. [44]. With regard to Gln, which is exclusively synthesized in astrocytes, its relatively high labelling from acetate supports the preferred [45], albeit not exclusive [30,32] astrocytic metabolism of acetate.

Most previous studies in which MSO was found to significantly affect generation of Glu from $\left[{ }^{13} \mathrm{C}\right]$ metabolic intermediates (glucose and/or acetate) have analyzed effects of direct application of MSO to in vitro preparations, at concentrations ranging from 1 to 10 $\mathrm{mM}$ [30-32]. Significant reduction of ${ }^{13} \mathrm{C}$ glucose flux in the brain in vivo was reported upon $6 \mathrm{~h}$ after injection of $150 \mathrm{mg} / \mathrm{kg}$ MSO i.p. [24], which is a sub-acute dose reported to cause convulsion [46]. The here used $75 \mathrm{mg} / \mathrm{kg}$ i.p. dose of MSO administered for 165-210 min was comparatively low, likely below the threshold required to produce a significant effect. It is intriguing, however, that the reduction of ${ }^{13} \mathrm{C}$-enrichment of Gln and Glu from glucose at the 15 min time point by MSO found in control rats, was not observed in Pilotreated rats. The mechanism by which Pilo abrogated the effect of MSO could be related to deregulation of glucose metabolism. Depending upon the experimental setting, Piloinduced seizures in their initial phase are accompanied either by an increased [47-50] or decreased cerebral glucose uptake/consumption [51-53]. Whatever their direction, the changes in glucose metabolism inflicted by Pilo-induced seizures may interfere with the effects of MSO. It is likely that in the MSO+Pilo group, the effect of MSO is additionally masked by Pilo-evoked release of a large pool of unlabeled Glu, indeed, a small tendency towards decrease of a ${ }^{13} \mathrm{C}$ labelled Glu pool is noted at $15^{\prime}$ post-Pilo (Fig. 1. A.)

The observation that MSO added at a low, non-convulsive dose did not significantly affect the ${ }^{13} \mathrm{C}$-enrichment of Gln or Glu in Li-Pilo-stimulated brain slices substantiated investigation of GGC-bypassing effects of MSO on Glu release and uptake. The key observation made was that MSO markedly reduced the release of newly loaded $\left[{ }^{3} \mathrm{H}\right] \mathrm{D}-\mathrm{Asp}$ from ex vivo brain slices subjected to the isotonic depolarization stimulus $(75 \mathrm{mM} \mathrm{K})$. $\left[{ }^{3} \mathrm{H}\right] \mathrm{D}$-Asp release has been observed to mimic fairly well depolarization evoked release of the synaptic vesicular pool of Glu in brain slices [54] and cultured neurons [55]. Earlier, this paradigm proved useful in explaining variable responses of glutamatergic transmission in different models of hepatic encephalopathy [56]. The present results suggest that in the Li-Pilo-treated rats in situ, MSO attenuated the glutamatergic aspect of the initial seizures by directly inhibiting Glu release, albeit interactive interference of MSO and Pilo with the with the metabolism of Glu precursors to Glu described in the previous paragraph cannot be excluded. Since induction and propagation of seizures by Pilo is subject to a complex mechanism encompassing a yet not fully resolved interplay of cholinergic and glutamatergic stimulation $[57,58]$, it is clear that the reduction of the release, noted in brain slices obtained from MSO-treated rats in response to a single depolarizing stimulus, can only be considered as a rough approximation of its seizure-attenuating effect of Pilo in situ. Of note, basal, unstimulated $\left[{ }^{3} \mathrm{H}\right] \mathrm{D}-\mathrm{Asp}$ release from the slices was not affected by MSO exposure (Fig. 3.), a finding contrasting with stimulation of Glu release observed in different experimental settings at pro-convulsive MSO doses [33,35]. The above discrepancy underscores the dose-dependent duality of the effects of MSO.

VGLUT1 is the principal vesicular Glu transporter responsible for loading synaptic vesicles with glutamate, and as such a specific marker for the glutamatergic networks [36]. Notably, VGLUT1 is present in all intrinsic glutamatergic types of neurons of hippocampus [59], the structure involved in generation of seizures by pilocarpine and other chemical stimulants [60]. The decrease of VGLUT1 protein content by MSO may thus underlie the attenuation of $\left[{ }^{3} \mathrm{H}\right] \mathrm{D}$-Asp release observed in brain slices obtained from MSO-treated rats. The mechanism underlying MSO-induced VGLUT1 protein loss remains to be re- 
solved. MSO may affect VGLUT1 protein synthesis or degradation directly, but alternatively or in addition, the response may be secondary to MSO-induced loss of a pertinent pool of synaptic Glu and/or Gln.

Increase of VGLUT1 protein has been recorded in autopsied hippocampi of human patients suffering from chronic TLE [61] and of rats in which pilocarpine treatment led to the development of SRS [62]. Whether the MSO-induced decrease of VGLUT1 contributes to the glutamatergic aspect of pilocarpine-induced initial seizures remains to be unequivocally proven: the caveats to this interpretation are the same as those outlined above with regard to the $\left[{ }^{3} \mathrm{H}\right] \mathrm{D}$-Asp release study. If this interpretation is correct, and the decrease is sustained throughout development of TLE to its full-blown stage, MSO would be a valuable addition to the hotly debated list of antiepileptic drugs with antiepileptogenic activity [63]. The fact that MSO is relatively much less neurotoxic in primates than in rodents [9] substantiates further search into its antiepileptogenic potential.

It cannot be excluded that modulation by MSO of glutamatergic transmission involves other Gln synthesis-bypassing mechanisms as well. MSO inhibits not only GS, but also $\gamma$-glutamylcysteine synthetase, an enzyme diverting a significant portion of Glu towards glutathione synthesis [64]. MSO was also found to variably affect Gln fluxes in cultured astrocytes [65], and brain cortex slices [66]. However, the above mentioned findings were obtained in experimental conditions not easily translatable to those recorded in $e x$ vivo slices in the present study.

In conclusion, notwithstanding a number of caveats to be resolved, the results of the present study may be best interpreted as indicating that MSO at a non-convulsive dose mitigates the initial Pilo-induced seizures by interfering with mechanism of Glu release. By contrast, the results do not support the view that the "canonical" glutamine synthetaseinhibiting activity of MSO plays an essential role in the attenuation of the seizures at this stage.

\section{Materials and Methods}

\subsection{Juvenile rat Li+-pilocarpine TLE model}

The procedure was essentially as described previously [1,67] with minor modifications. At postnatal day 23 (P23), male Sprague Dawley rats (the animal colony of the Mossakowski Medical Research Institute, Polish Academy of Sciences in Warsaw) were injected intraperitoneally (i.p.) with lithium carbonate $(222 \mathrm{mg} / \mathrm{kg}$; Sigma) dissolved in saline ( $\mathrm{pH}$ equalized to 7.4). At P24, 18-20h after Li+ treatment, animals were injected i.p. with methyl-scopolamine ( $1 \mathrm{mg} / \mathrm{kg}$; Sigma) and thirty minutes later with pilocarpine (Pilo (40 mg/kg; Sigma). From then on, animal's behavior was continuously monitored. Rats were decapitated either 15' (onset phase) or 60' (final phase) after Pilo administration (see also paragraph 4.3).

\subsection{Pretreatment with $\mathrm{MSO}$}

MSO (Sigma) was dissolved in saline and administered i.p. at $75 \mathrm{mg} / \mathrm{kg}$. Rats that were used in experiments with Pilo received MSO $150 \mathrm{~min}$ before Pilo, thus 165 min or $210 \mathrm{~min}$ before decapitation. Rats that were used in experiments with Pilo received MSO $150 \mathrm{~min}$ before Pilo, thus $165 \mathrm{~min}$ (Fig. 1., 2. A-D) or $210 \mathrm{~min}$ (Fig. 1., 2. E-H, Fig. 4) before decapitation. Rats used for ex vivo experiments with brain slices received MSO $210 \mathrm{~min}$ before decapitation (Fig. 3.). Control rats that did not receive MSO were given equal volumes of saline at the same time.

\subsection{Metabolic studies in vivo}

The following procedures were based on previously published papers $[27,68]$. Rats divided into four groups (control, MSO, Pilo, MSO+Pilo) received a single i.p. dose of [U$\left.{ }^{13} \mathrm{C}\right]$ glucose $\left(543 \mathrm{mg} / \mathrm{kg}\right.$ ) or $\left[1,2-{ }^{13} \mathrm{C}\right]$ acetate $(504 \mathrm{mg} / \mathrm{kg})$ (Cambridge Isotope Laboratories) dissolved in saline, either at the same time as Pilo (onset) or 45 minutes after the injection 
of Pilo (final phase). All animals were decapitated after 15 minutes. Therefore the precursors were present in the body at the onset and in the final phase of Pilo action. Brain tissue was immediately dissected and frozen in liquid nitrogen. Frozen hippocampi and entorhinal cortex samples were homogenized in $2 \mathrm{~mL}$ of ice-cold $70 \%$ ethanol and then centrifuged for $20 \mathrm{~min}$ at 20,000 x g. Supernatant was collected, lyophilized, and used for amino acids analysis in GC-MS and HPLC; pellets were used for protein determination with the BCA assay (Thermo Fisher Scientific).

4.3.1. Metabolic mapping using gas chromatography coupled to mass spectrometry (GCMS)

Lyophilized extracts from hippocampus and entorhinal cortex tissue were resuspended, acidified to $\mathrm{pH}$ 1-2 with $\mathrm{HCl}$ and subsequently evaporated to dryness using nitrogen. With the use of $96 \%$ ethanol and benzene, the analytes were extracted, evaporated again to dryness and derivatized with $14 \%$ DMF/ 86 \% MTBSTFA [69]. Gas chromatography (GC, Agilent Technologies 7820A chromatograph, J\&W GC column HP-5MS, parts no. 19091S-433) coupled to mass spectrometry (MS, Agilent Technologies, 5977E) was used to separate and analyze the samples. With the use of unlabeled standards, metabolites of interest were corrected to their ${ }^{13} \mathrm{C}$ natural abundance in order to assess their isotopic enrichment. Calculations were performed according to [70]. Data integration and enrichment determination was performed with the software MassHunter Quantitative Analysis software v.6.0.3881 (Agilent Technologies). Data is presented as labelling (\%) of $\mathrm{M}+\mathrm{X}$, where $\mathrm{M}$ is the mass of the unlabelled molecule and $\mathrm{X}$ is the number of labelled Catoms in a given metabolite.

\subsubsection{Quantitative determination of intracellular amino acids by HPLC}

Tissue extracts, previously resuspended in water, were separated by reverse-phase high performance liquid chromatography (HPLC) using an Agilent ZORBAX Eclipse plus C18 column (4.6 × 150 mm, particle size $3.5 \mu \mathrm{m}$; 959,963-902, Agilent Technologies, Santa Clara, CA, USA) in an Agilent 1260 Infinity system coupled to a 1260 Infinity fluorescence detector (Agilent Technologies) as described previously [71]. Briefly, samples were derivatized with o-phthaldialdehyde and separation was performed with a mobile phase gradient consisting of a mixture of buffer A (10 mM Na $\mathrm{HPO}_{4}: 10 \mathrm{mM} \mathrm{Na} 2 \mathrm{~B}_{4} \mathrm{O}_{7}, \mathrm{pH} 6.9 ; 5$ $\mathrm{mM} \mathrm{NaN}_{3}$ ) and buffer $\mathrm{B}$ (acetonitrile $45 \%$ : methanol $45 \%$ : water $10 \%$, v:v:v). Amino acids quantification was performed using standards containing a mixture of the amino acids of interest on increasing concentrations. The acquired data was normalized to the protein concentration in the dry tissue samples. Effects of MSO on the Gln content could not be accurately assessed because the position of the MSO peak which was in much excess over Gln largely overlapped with the position of the latter.

\subsection{Metabolic studies ex vivo on acute brain slices}

Rats anesthetized with isoflurane (Baxter) were decapitated, the brain was immediately removed, and cortices were cut into $350 \mu \mathrm{m}$ thick slices, using McIllwain tissue chopper. The slices were pre-incubated for 30 minutes in the Krebs buffer $\left(37^{\circ} \mathrm{C}\right.$, aerated with $95 \% \mathrm{O} 2$ and 5\%CO2, pH 7.4 ), composed of [mM]: $118 \mathrm{NaCl}, 25 \mathrm{NaHCO}_{3}, 4.7 \mathrm{KCl}, 1.2$ $\mathrm{KH}_{2} \mathrm{PO}_{4}, 2.5 \mathrm{CaCl}_{2}, 1.2 \mathrm{MgSO}_{4}, 10$ glucose. After preincubation, slices were used either for uptake or efflux measurement protocols, employing the radioactive $\left[{ }^{3} \mathrm{H}\right] \mathrm{D}$-Aspartate $\left(\left[{ }^{3} \mathrm{H}\right] \mathrm{D}-\mathrm{Asp}\right)$ as the non-metabolised analogue of glutamate.

\subsection{1. $\left[{ }^{3} \mathrm{H}\right] \mathrm{D}$-Asp efflux assay}

The $\left[{ }^{3} \mathrm{H}\right] \mathrm{D}$-Asp efflux was assayed based on the method previously described [72], with modifications. $\left[{ }^{3} \mathrm{H}\right] \mathrm{D}$-Asp efflux was measured after 15 minutes incubation in Krebs buffer containing $1.4 \mu \mathrm{Ci} / \mathrm{mL}\left[{ }^{3} \mathrm{H}\right] \mathrm{D}$-Asp (Perkin-Elmer) and unlabeled D-Asp (100 $\mu \mathrm{mol} / \mathrm{L}$ ). The slices were moved to a chamber perfusion system (Brandel) and rinsed with Krebs buffer at $0,5 \mathrm{~mL} / \mathrm{min}$ rate. The initial fraction was collected for $20 \mathrm{~min}$ to establish baseline efflux. Perfusate samples were then collected for $20 \mathrm{~min}$, at $1 \mathrm{~min}$ intervals. At 
the time period indicated in Figure . A. (fractions 5 and 6), a depolarizing pulse was introduced by raising $\mathrm{KCl}$ concentration in the Krebs buffer to $75 \mathrm{mM}$, with simultaneous reduction of $\mathrm{NaCl}$ to $47.7 \mathrm{mM}$ ). Radioactivity contained in the preparation and released from brain slices were measured by a Wallac 1409 Liquid Scintillation Counter (PerkinElmer).

\subsection{2. $\left[{ }^{3} \mathrm{H}\right] \mathrm{D}-\mathrm{Asp}$ uptake assay}

The $\left[{ }^{3} \mathrm{H}\right] \mathrm{D}$-Asp uptake was assayed as previously described [73]. Briefly, the uptake was initiated by adding [ $\left.{ }^{3} \mathrm{H}\right] \mathrm{D}-\mathrm{Asp}, 0.1 \mu \mathrm{Ci} / 1 \mathrm{~mL}$ (Perkin-Elmer), to varying extracellular concentrations of unlabelled D-Asp $(50-2000 \mu \mathrm{M})$. The incubation with the radioisotope was continued for $3 \mathrm{~min}$ and was terminated by rapid vacuum filtration through nitrocellulose filter disks (Millipore), followed by flushing four times with $2 \mathrm{~mL}$ of ice-cold Krebs buffer. The slices were weighed, immersed in $4 \mathrm{~mL}$ of InstaGel scintillation fluid (PerkinElmer), and the radioactivity of slices on filter disks was measured in the Wallac 1409 Liquid Scintillation Counter (Perkin-Elmer).

\subsection{VGluT1 analysis}

\subsubsection{RT-qPCR}

Total RNA was isolated from hippocampus using TRI Reagent (Sigma). Extracted RNA was reversely transcribed using High-Capacity cDNA Reverse Transcription Kit (Applied Biosystems). The mRNA expression was determined by Taqman Gene Expression Assays (Applied Biosystems), using $1 \mu \mathrm{l}$ of cDNA in a reaction of $10 \mu \mathrm{l}$. The assay IDs were Rn01462431_m1 for rat VGLUT1 and Rn00667869_m1 for $\beta$-actin. The fold change in the gene expression was determined by the $2^{-\Delta \Delta \mathrm{Ct}}$ method [74].

\subsubsection{Western Blotting}

After decapitation, immediately removed rat hippocampus was isolated on ice and snap-frozen in liquid nitrogen. Frozen tissue samples were homogenized in buffer and centrifuged as described by Popek et al. [75]. Protein concentrations were performed using a BCA Protein Assay (Thermo Fisher Scientific). The content of VGluT1 protein was assessed by Western Blotting as previously described [75,76]. Membranes were incubated overnight at $4^{\circ} \mathrm{C}$ with anti-VgluT1 antibody (cat. no. EPR22269, 1:1000) (Abcam), washed, incubated with HRP-conjugated IgG (cat. no. 269A-1 1:5000) (Sigma) and developed using Chemiluminescent Super Signal West Pico Substrate (Pierce). After stripping, the membranes were incubated with HRP-conjugated anti-GAPDH antibody for $1 \mathrm{~h}$ (cat. no. HRP60004, 1:10000) (Proteintech), which was used as a loading control, and developed as described above. Data were expressed as percentage change in fluorescent band intensity of VGLUT1 antibody divided by GAPDH.

\subsection{Data evaluation}

All statistical analysis were performed with Prism 7.0 (GraphPad) software. T-tests were used for comparisons of two groups and one-way ANOVA for more than two groups. Multiple comparisons were followed by Holm-Šidák's (multiple t-tests) or Tukey's (ANOVA) post hoc tests. The significance level was set at $p<0.05$.

Author Contributions: Conceptualization, J.A.; methodology, J.A., B.I.A., M.O.-M., M.P.P, M.J.P; validation, M.J.P, J.A.; formal analysis, M.J.P, M.O.-M.; investigation, M.J.P., M.O.-M., M.P.P., L.F.B.C.; resources, J.A., B.I.A.; data curation, M.J.P.; writing-original draft preparation, J.A., M.J.P., M.O.-M., M.P.P., B.I.A; writing - review and editing, J.A., M.J.P., M.O.-M., B.I.A, A.M.C., L.F.B.-C.; visualization, M.J.P., B.I.A; supervision, J.A.; project administration, J.A., M.J.P., M.O.-M.; funding acquisition, J.A., M.J.P. All authors have read and agreed to the published version of the manuscript.

Funding: This work was supported by the National Science Centre (NCN) of Poland (2016/23/B/NZ4/03678) and by ESF (POWR.03.02.00-00-I028/17-00).

Institutional Review Board Statement: Animal experiments were conducted according to the guidelines of the Declaration of Helsinki and the national guidelines on animal experimentation, 
and were approved by the local ethical committee in Warsaw (consent no. 405/2017, 21.11.2017) in accordance with EC Directive 2010/63/EU.

Informed Consent Statement: Not applicable.

Data Availability Statement: Data available on request.

Acknowledgments: The authors would like to thank Dr Jolanta Dyniewicz and Katarzyna Kosińska from the Department of Neuropeptides of MMRI PAS for their invaluable help with samples lyophilisation.

Conflicts of Interest: The authors declare no conflict of interest.

\section{References}

1. Pawlik, M.J.; Obara-Michlewska, M.; Popek, M.P.; Czarnecka, A.M.; Czuczwar, S.J.; Łuszczki, J.; Kołodziej, M.; Acewicz, A.; Wierzba-Bobrowicz, T.; Albrecht, J. Pretreatment with a glutamine synthetase inhibitor MSO delays the onset of initial seizures induced by pilocarpine in juvenile rats. Brain Res. 2021, 1753, doi:10.1016/j.brainres.2020.147253.

2. Bak, L.K.; Schousboe, A.; Waagepetersen, H.S. The glutamate/GABA-glutamine cycle: Aspects of transport, neurotransmitter homeostasis and ammonia transfer. J. Neurochem. 2006, 98, 641-653.

3. Schousboe, A.; Bak, L.K.; Waagepetersen, H.S. Astrocytic control of biosynthesis and turnover of the neurotransmitters glutamate and GABA. Front. Endocrinol. (Lausanne). 2013, 4, 1-11, doi:10.3389/fendo.2013.00102.

4. Chaudhry, F.A.; Reimer, R.J.; Edwards, R.H. The glutamine commute: take the N line and transfer to the A. J. Cell Biol. 2002, 157, 349-355, doi:10.1083/jcb.200201070.

5. Chaudhry, F.A.; Schmitz, D.; Reimer, R.J.; Larsson, P.; Gray, A.T.; Nicoll, R.; Kavanaugh, M.; Edwards, R.H. Glutamine uptake by neurons: interaction of protons with system a transporters. J. Neurosci. 2002, 22, 62-72, doi:10.1523/JNEUROSCI.2201-00062.2002.

6. Jenstad, M.; Quazi, A.Z.; Zilberter, M.; Haglerød, C.; Berghuis, P.; Saddique, N.; Goiny, M.; Buntup, D.; Davanger, S.; S Haug, F.-M.; et al. System A transporter SAT2 mediates replenishment of dendritic glutamate pools controlling retrograde signaling by glutamate. Cereb. Cortex 2009, 19, 1092-1106, doi:10.1093/cercor/bhn151.

7. Rowe, W.B.; Meister, A. Identification of L-methionine-S-sulfoximine as the convulsant isomer of methionine sulfoximine. Proc. Natl. Acad. Sci. U. S. A. 1970, 66, 500-506, doi:10.1073/pnas.66.2.500.

8. Eid, T.; Ghosh, A.; Wang, Y.; Beckstrom, H.; Zaveri, H.P.; Lee, T.-S.W.; Lai, J.C.K.; Malthankar-Phatak, G.H.; de Lanerolle, N.C. Recurrent seizures and brain pathology after inhibition of glutamine synthetase in the hippocampus in rats. Brain 2008, 131, 2061-2070, doi:10.1093/brain/awn133.

9. Brusilow, W.S.A.; Peters, T.J. Therapeutic effects of methionine sulfoximine in multiple diseases include and extend beyond inhibition of glutamine synthetase. Expert Opin. Ther. Targets 2017, 21, 461-469, doi:10.1080/14728222.2017.1303484.

10. Perez, E.L.; Lauritzen, F.; Wang, Y.; Lee, T.S.W.; Kang, D.; Zaveri, H.P.; Chaudhry, F.A.; Ottersen, O.P.; Bergersen, L.H.; Eid, T. Evidence for astrocytes as a potential source of the glutamate excess in temporal lobe epilepsy. Neurobiol. Dis. 2012, 47, 331-337, doi:10.1016/j.nbd.2012.05.010.

11. Albright, B.; Dhaher, R.; Wang, H.; Harb, R.; Lee, T.S.W.; Zaveri, H.; Eid, T. Progressive neuronal activation accompanies epileptogenesis caused by hippocampal glutamine synthetase inhibition. Exp. Neurol. 2017, 288, 122-133, doi:10.1016/j.expneurol.2016.10.007.

12. Wang, H.; Huang, Y.; Coman, D.; Munbodh, R.; Dhaher, R.; Zaveri, H.P.; Hyder, F.; Eid, T. Network evolution in mesial temporal lobe epilepsy revealed by diffusion tensor imaging. Epilepsia 2017, 58, 824-834, doi:10.1111/epi.13731.

13. van der Hel, W.S.; Notenboom, R.G.E.; Bos, I.W.M.; van Rijen, P.C.; van Veelen, C.W.M.; de Graan, P.N.E. Reduced glutamine synthetase in hippocampal areas with neuron loss in temporal lobe epilepsy. Neurology 2005, 64, 326-333, doi:10.1212/01.WNL.0000149636.44660.99. 
14. Kang, T.-C.; Kim, D.-S.; Kwak, S.-E.; Kim, J.-E.; Won, M.H.; Kim, D.-W.; Choi, S.-Y.; Kwon, O.-S. Epileptogenic roles of astroglial death and regeneration in the dentate gyrus of experimental temporal lobe epilepsy. Glia 2006, 54, 258-271, doi:10.1002/glia.20380.

15. Papageorgiou, I.E.; Gabriel, S.; Fetani, A.F.; Kann, O.; Heinemann, U. Redistribution of astrocytic glutamine synthetase in the hippocampus of chronic epileptic rats. Glia 2011, 59, 1706-1718, doi:10.1002/glia.21217.

16. Boissonnet, A.; Hévor, T.; Cloix, J.-F. Phenotypic differences between fast and slow methionine sulfoximine-inbred mice: seizures, anxiety, and glutamine synthetase. Epilepsy Res. 2012, 98, 25-34, doi:10.1016/j.eplepsyres.2011.08.012.

17. Fleischer, W.; Theiss, S.; Schnitzler, A.; Sergeeva, O. Glutamine triggers long-lasting increase in striatal network activity in vitro. Exp. Neurol. 2017, 290, 41-52, doi:10.1016/j.expneurol.2017.01.003.

18. Sandow, N.; Zahn, R.K.; Gabriel, S.; Heinemann, U.; Lehmann, T.N. Glutamine induces epileptiform discharges in superficial layers of the medial entorhinal cortex from pilocarpine-treated chronic epileptic rats in vitro. Epilepsia 2009, 50, 849-858, doi:10.1111/j.1528-1167.2008.01973.x.

19. Kanamori, K.; Ross, B.D. Electrographic seizures are significantly reduced by in vivo inhibition of neuronal uptake of extracellular glutamine in rat hippocampus. Epilepsy Res. 2013, 107, 20-36, doi:10.1016/j.eplepsyres.2013.08.007.

20. Tani, H.; Dulla, C.G.; Huguenard, J.R.; Reimer, R.J. Glutamine is required for persistent epileptiform activity in the disinhibited neocortical brain slice. J. Neurosci. 2010, 30, 1288-300, doi:10.1523/JNEUROSCI.0106-09.2010.

21. Hülsmann, S.; Oku, Y.; Zhang, W.; Richter, D.W. Metabolic coupling between glia and neurons is necessary for maintaining respiratory activity in transverse medullary slices of neonatal mouse. Eur. J. Neurosci. 2000, 12, 856-862, doi:10.1046/j.14609568.2000.00973.x.

22. Bacci, A.; Sancini, G.; Verderio, C.; Armano, S.; Pravettoni, E.; Fesce, R.; Franceschetti, S.; Matteoli, M. Block of GlutamateGlutamine Cycle Between Astrocytes and Neurons Inhibits Epileptiform Activity in Hippocampus. J. Neurophysiol. 2002, 88, 2302-2310, doi:10.1152/jn.00665.2001.

23. Sun, H.L.; Zhang, S.H.; Zhong, K.; Xu, Z.H.; Feng, B.; Yu, J.; Fang, Q.; Wang, S.; Wu, D.C.; Zhang, J.M.; et al. A Transient Upregulation of Glutamine Synthetase in the Dentate Gyrus Is Involved in Epileptogenesis Induced by Amygdala Kindling in the Rat. PLoS One 2013, 8, 1-12, doi:10.1371/journal.pone.0066885.

24. García-Espinosa, M.A.; Rodrigues, T.B.; Sierra, A.; Benito, M.; Fonseca, C.; Gray, H.L.; Bartnik, B.L.; García-Martín, M.L.; Ballesteros, P.; Cerdán, S. Cerebral glucose metabolism and the glutamine cycle as detected by in vivo and in vitro 13C NMR spectroscopy. Neurochem. Int. 2004, 45, 297-303, doi:10.1016/j.neuint.2003.08.014.

25. Melø, T.M.; Nehlig, A.; Sonnewald, U. Metabolism is normal in astrocytes in chronically epileptic rats: a (13)C NMR study of neuronal-glial interactions in a model of temporal lobe epilepsy. J. Cereb. blood flow Metab. Off. J. Int. Soc. Cereb. Blood Flow Metab. 2005, 25, 1254-1264, doi:10.1038/sj.jcbfm.9600128.

26. Hadera, M.G.; Faure, J.-B.; Berggaard, N.; Tefera, T.W.; Nehlig, A.; Sonnewald, U. The anticonvulsant actions of carisbamate associate with alterations in astrocyte glutamine metabolism in the lithium-pilocarpine epilepsy model. J. Neurochem. 2015, 132, 532-545, doi:10.1111/jnc.12977.

27. Walls, A.B.; Eyjolfsson, E.M.; Schousboe, A.; Sonnewald, U.; Waagepetersen, H.S. A subconvulsive dose of kainate selectively compromises astrocytic metabolism in the mouse brain in vivo. J. Cereb. Blood Flow Metab. 2014, 34, 1340-1346, doi:10.1038/jcbfm.2014.88.

28. Aldana, B.I.; Zhang, Y.; Jensen, P.; Chandrasekaran, A.; Christensen, S.K.; Nielsen, T.T.; Nielsen, J.E.; Hyttel, P.; Larsen, M.R.; Waagepetersen, H.S.; et al. Glutamate-glutamine homeostasis is perturbed in neurons and astrocytes derived from patient iPSC models of frontotemporal dementia. Mol. Brain 2020, 13, 1-17, doi:10.1186/s13041-020-00658-6.

29. Andersen, J. V.; Christensen, S.K.; Westi, E.W.; Diaz-delCastillo, M.; Tanila, H.; Schousboe, A.; Aldana, B.I.; Waagepetersen, H.S. Deficient astrocyte metabolism impairs glutamine synthesis and neurotransmitter homeostasis in a mouse model of 
Alzheimer's disease. Neurobiol. Dis. 2021, 148, 105198, doi:10.1016/j.nbd.2020.105198.

30. Andersen, J.V.; McNair, L.F.; Schousboe, A.; Waagepetersen, H.S. Specificity of exogenous acetate and glutamate as astrocyte substrates examined in acute brain slices from female mice using methionine sulfoximine (MSO) to inhibit glutamine synthesis. J. Neurosci. Res. 2017, 95, 2207-2216, doi:10.1002/jnr.24038.

31. Sonnewald, U.; Westergaard, N.; Schousboe, A.; Svendsen, J.S.; Unsgård, G.; Petersen, S.B. Direct demonstration by [13C]NMR spectroscopy that glutamine from astrocytes is a precursor for GABA synthesis in neurons. Neurochem. Int. 1993, 22, 19-29, doi:10.1016/0197-0186(93)90064-C.

32. Rowlands, B.D.; Klugmann, M.; Rae, C.D. Acetate metabolism does not reflect astrocytic activity, contributes directly to GABA synthesis, and is increased by silent information regulator 1 activation. J. Neurochem. 2017, 140, 903-918, doi:10.1111/jnc.13916.

33. Rothstein, J.D.; Tabakoff, B. Glial and neuronal glutamate transport following glutamine synthetase inhibition. Biochem. Pharmacol. 1985, 34, 73-79, doi:10.1016/0006-2952(85)90102-9.

34. McBean, G.J. Inhibition of the glutamate transporter and glial enzymes in rat striatum by the gliotoxin, ocaminoadipate. $\mathrm{Br}$. J. Pharmacol. 1994, 113, 536-540, doi:10.1111/j.1476-5381.1994.tb17022.x.

35. Shaw, C.A.; Bains, J.S.; Pasqualotto, B.A.; Curry, K. Methionine sulfoximine shows excitotoxic actions in rat cortical slices. Can. J. Physiol. Pharmacol. 1999, 77, 871-877, doi:10.1139/y99-097.

36. Pietrancosta, N.; Djibo, M.; Daumas, S.; El Mestikawy, S.; Erickson, J.D. Molecular, Structural, Functional, and Pharmacological Sites for Vesicular Glutamate Transporter Regulation. Mol. Neurobiol. 2020, 57, 3118-3142, doi:10.1007/s12035-020-01912-7.

37. Takahashi, H.; Koehler, R.C.; Brusilow, S.W.; Traystman, R.J. Inhibition of brain glutamine accumulation prevents cerebral edema in hyperammonemic rats. Am. J. Physiol. 1991, 261, H825-9, doi:10.1152/ajpheart.1991.261.3.H825.

38. Toyoda, I.; Bower, M.R.; Leyva, F.; Buckmaster, P.S. Early activation of ventral hippocampus and subiculum during spontaneous seizures in a rat model of temporal lobe epilepsy. J. Neurosci. 2013, 33, 11100-11115, doi:10.1523/JNEUROSCI.0472-13.2013.

39. Jeitner, T.M.; Cooper, A.J.L. Inhibition of human glutamine synthetase by L-methionine-S,R-sulfoximine-relevance to the treatment of neurological diseases. Metab. Brain Dis. 2014, 29, 983-989, doi:10.1007/s11011-013-9439-6.

40. Kam, K.; Nicoll, R. Excitatory synaptic transmission persists independently of the glutamate-glutamine cycle. J. Neurosci. 2007, 27, 9192-9200, doi:10.1523/JNEUROSCI.1198-07.2007.

41. Sonnewald, U. Glutamate synthesis has to be matched by its degradation - where do all the carbons go? J. Neurochem. 2014, 131, 399-406, doi:10.1111/jnc.12812.

42. Yu, A.C.; Drejer, J.; Hertz, L.; Schousboe, A. Pyruvate carboxylase activity in primary cultures of astrocytes and neurons. J. Neurochem. 1983, 41, 1484-1487, doi:10.1111/j.1471-4159.1983.tb00849.x.

43. Faff-Michalak, L.; Albrecht, J. Aspartate aminotransferase, malate dehydrogenase, and pyruvate carboxylase activities in rat cerebral synaptic and nonsynaptic mitochondria: effects of in vitro treatment with ammonia, hyperammonemia and hepatic encephalopathy. Metab. Brain Dis. 1991, 6, 187-197, doi:10.1007/BF00996918.

44. Schousboe, A.; Waagepetersen, H.S.; Sonnewald, U. Astrocytic pyruvate carboxylation: Status after 35 years. J. Neurosci. Res. 2019, 97, 890-896, doi:10.1002/jnr.24402.

45. Waniewski, R.A.; Martin, D.L. Preferential utilization of acetate by astrocytes is attributable to transport. J. Neurosci. 1998, 18, 5225-5233, doi:10.1523/JNEUROSCI.18-14-05225.1998.

46. Jessy, J.; Murthy, C.R. Branched chain amino acid transaminases in brain in methionine sulphoximine (MSI) toxicity. Biochem. Int. 1988, 16, 245-251.

47. Motte, J.; Fernandes, M.J.D.S.; Baram, T.Z.; Nehlig, A. Spatial and temporal evolution of neuronal activation, stress and injury 
in lithium-pilocarpine seizures in adult rats. Brain Res. 1998, 793, 61-72, doi:10.1016/S0006-8993(98)00135-8.

48. Yamada, A.; Momosaki, S.; Hosoi, R.; Abe, K.; Yamaguchi, M.; Inoue, O. Glucose utilization in the brain during acute seizure is a useful biomarker for the evaluation of anticonvulsants: effect of methyl ethyl ketone in lithium-pilocarpine status epilepticus rats. Nucl. Med. Biol. 2009, 36, 949-954, doi:10.1016/j.nucmedbio.2009.06.008.

49. Hosoi, R.; Kitano, D.; Momosaki, S.; Kuse, K.; Gee, A.; Inoue, O. Remarkable increase in 14C-acetate uptake in an epilepsy model rat brain induced by lithium-pilocarpine. Brain Res. 2010, 1311, 158-165, doi:10.1016/j.brainres.2009.10.074.

50. Imran, I.; Hillert, M.H.; Klein, J. Early metabolic responses to lithium/pilocarpine-induced status epilepticus in rat brain. J. Neurochem. 2015, 135, 1007-1018, doi:10.1111/jnc.13360.

51. Guo, Y.; Gao, F.; Wang, S.; Ding, Y.; Zhang, H.; Wang, J.; Ding, M.-P. In vivo mapping of temporospatial changes in glucose utilization in rat brain during epileptogenesis: an 18F-fluorodeoxyglucose-small animal positron emission tomography study. Neuroscience 2009, 162, 972-979, doi:10.1016/j.neuroscience.2009.05.041.

52. Lee, E.M.; Park, G.Y.; Im, K.C.; Kim, S.T.; Woo, C.-W.; Chung, J.H.; Kim, K.S.; Kim, J.S.; Shon, Y.-M.; Kim, Y.I.; et al. Changes in glucose metabolism and metabolites during the epileptogenic process in the lithium-pilocarpine model of epilepsy. Epilepsia 2012, 53, 860-869, doi:10.1111/j.1528-1167.2012.03432.x.

53. Kim, H.; Choi, Y.; Joung, H.; Choi, Y.S.; Kim, H.J.; Joo, Y.; Oh, J.; Hann, H.J.; Cho, Z.; Lee, H.W. Structural and Functional Alterations at Pre-Epileptic Stage Are Closely Associated with Epileptogenesis in Pilocarpine-induced Epilepsy Model. Exp. Neurobiol. 2017, 26, 287-294.

54. Savage, D.D.; Galindo, R.; Queen, S.A.; Paxton, L.L.; Allan, A.M. Characterization of electrically evoked [3H]-D-aspartate release from hippocampal slices. Neurochem. Int. 2001, 38, 255-267, doi:10.1016/S0197-0186(00)00077-2.

55. Cousin, M.A.; Hurst, H.; Nicholls, D.G. Presynaptic calcium channels and field-evoked transmitter exocytosis from cultured cerebellar granule cells. Neuroscience 1997, 81, 151-161, doi:10.1016/S0306-4522(97)00047-X.

56. Hilgier, W.; Haugvicova, R.; Albrecht, J. Decreased potassium-stimulated release of [3H]D-aspartate from hippocampal slices distinguishes encephalopathy related to acute liver failure from that induced by simple hyperammonemia. Brain Res. 1991, 567, 165-168, doi:10.1016/0006-8993(91)91451-6.

57. Hillert, M.H.; Imran, I.; Zimmermann, M.; Lau, H.; Weinfurter, S.; Klein, J. Dynamics of hippocampal acetylcholine release during lithium-pilocarpine-induced status epilepticus in rats. J. Neurochem. 2014, 131, 42-52, doi:10.1111/jnc.12787.

58. Meller, S.; Brandt, C.; Theilmann, W.; Klein, J.; Löscher, W. Commonalities and differences in extracellular levels of hippocampal acetylcholine and amino acid neurotransmitters during status epilepticus and subsequent epileptogenesis in two rat models of temporal lobe epilepsy. Brain Res. 2019, 1712, 109-123, doi:10.1016/j.brainres.2019.01.034.

59. Fremeau, R.T.J.; Kam, K.; Qureshi, T.; Johnson, J.; Copenhagen, D.R.; Storm-Mathisen, J.; Chaudhry, F.A.; Nicoll, R.A.; Edwards, R.H. Vesicular glutamate transporters 1 and 2 target to functionally distinct synaptic release sites. Science 2004, 304, 1815-1819, doi:10.1126/science.1097468.

60. Sharma, A.K.; Reams, R.Y.; Jordan, W.H.; Miller, M.A.; Thacker, H.L.; Snyder, P.W. Mesial temporal lobe epilepsy: pathogenesis, induced rodent models and lesions. Toxicol. Pathol. 2007, 35, 984-999, doi:10.1080/01926230701748305.

61. van der Hel, W.S.; Verlinde, S.A.M.W.; Meijer, D.H.M.; de Wit, M.; Rensen, M.G.; van Gassen, K.L.I.; van Rijen, P.C.; van Veelen, C.W.M.; de Graan, P.N.E. Hippocampal distribution of vesicular glutamate transporter 1 in patients with temporal lobe epilepsy. Epilepsia 2009, 50, 1717-1728, doi:10.1111/j.1528-1167.2009.02054.x.

62. Boulland, J.-L.; Ferhat, L.; Tallak Solbu, T.; Ferrand, N.; Chaudhry, F.A.; Storm-Mathisen, J.; Esclapez, M. Changes in vesicular transporters for gamma-aminobutyric acid and glutamate reveal vulnerability and reorganization of hippocampal neurons following pilocarpine-induced seizures. J. Comp. Neurol. 2007, 503, 466-485, doi:10.1002/cne.21384.

63. Miziak, B.; Konarzewska, A.; Ułamek-Kozioł, M.; Dudra-Jastrzębska, M.; Pluta, R.; Czuczwar, S.J. Anti-epileptogenic effects of antiepileptic drugs. Int. J. Mol. Sci. 2020, 21, 2340, doi:10.3390/ijms21072340. 
64. Meister, A.; Tate, S.S. Glutathione and related gamma-glutamyl compounds: biosynthesis and utilization. Annu. Rev. Biochem. 1976, 45, 559-604, doi:10.1146/annurev.bi.45.070176.003015.

65. Albrecht, J.; Norenberg, M.D. L-Methionine-DL-sulfoximine induces massive efflux of glutamine from cortical astrocytes in primary culture. Eur. J. Pharmacol. 1990, 182, 587-590, doi:10.1016/0014-2999(90)90061-A.

66. Zielińska, M.; Stafiej, A.; Law, R.O.; Albrecht, J. Effects of methionine sulfoximine on the glutamine and glutamate content and cell volume in rat cerebral cortical slices: Involvement of mechanisms not related to inhibition of glutamine synthesis. Neurotoxicology 2004, 25, 443-449, doi:10.1016/j.neuro.2003.10.003.

67. van der Hel, W.S.; Hessel, E.V.S.; Bos, I.W.M.; Mulder, S.D.; Verlinde, S.A.M.W.; van Eijsden, P.; de Graan, P.N.E. Persistent reduction of hippocampal glutamine synthetase expression after status epilepticus in immature rats. Eur. J. Neurosci. 2014, 40, 3711-3719, doi:10.1111/ejn.12756.

68. Alvestad, S.; Hammer, J.; Qu, H.; Haberg, A.; Ottersen, O.P.; Sonnewald, U. Reduced astrocytic contribution to the turnover of glutamate, glutamine, and GABA characterizes the latent phase in the kainate model of temporal lobe epilepsy. J. Cereb. Blood Flow Metab. 2011, 31, 1775-1786, doi:10.1038/jcbfm.2011.36.

69. Mawhinney, T.P.; Robinett, R.S.; Atalay, A.; Madson, M.A. Gas-liquid chromatography and mass spectral analysis of mono-, di- and tricarboxylates as their tert.-butyldimethylsilyl derivatives. J. Chromatogr. 1986, 361, 117-130, doi:10.1016/s00219673(01)86899-0.

70. Biemann, K. Mass spectrometry in organic chemistry applications; McGraw-Hill: New York, 1962;

71. Aldana, B.I.; Zhang, Y.; Lihme, M.F.; Bak, L.K.; Nielsen, J.E.; Holst, B.; Hyttel, P.; Freude, K.K.; Waagepetersen, H.S. Characterization of energy and neurotransmitter metabolism in cortical glutamatergic neurons derived from human induced pluripotent stem cells: A novel approach to study metabolism in human neurons. Neurochem. Int. 2017, 106, 48-61, doi:https://doi.org/10.1016/j.neuint.2017.02.010.

72. Hamdani, E.H.; Popek, M.; Frontczak-Baniewicz, M.; Utheim, T.P.; Albrecht, J.; Zielińska, M.; Chaudhry, F.A. Perturbation of astroglial Slc38 glutamine transporters by $\mathrm{NH}(4)(+)$ contributes to neurophysiologic manifestations in acute liver failure. FASEB J. Off. Publ. Fed. Am. Soc. Exp. Biol. 2021, 35, e21588, doi:10.1096/fj.202001712RR.

73. Dabrowska, K.; Skowronska, K.; Popek, M.; Obara-Michlewska, M.; Albrecht, J.; Zielinska, M. Roles of Glutamate and Glutamine Transport in Ammonia Neurotoxicity: State of the Art and Question Marks. Endocr. Metab. Immune Disord. Drug Targets 2018, 18, 306-315, doi:10.2174/1871520618666171219124427.

74. Livak, K.J.; Schmittgen, T.D. Analysis of relative gene expression data using real-time quantitative PCR and the $2-\Delta \Delta C T$ method. Methods 2001, 25, 402-408, doi:10.1006/meth.2001.1262.

75. Popek, M.; Bobula, B.; Sowa, J.; Hess, G.; Frontczak-Baniewicz, M.; Albrecht, J.; Zielińska, M. Physiology and Morphological Correlates of Excitatory Transmission are Preserved in Glutamine Transporter SN1-Depleted Mouse Frontal Cortex. Neuroscience 2020, 446, 124-136, doi:10.1016/j.neuroscience.2020.08.019.

76. Zielińska, M.; Dąbrowska, K.; Hadera, M.G.; Sonnewald, U.; Albrecht, J. System N transporters are critical for glutamine release and modulate metabolic fluxes of glucose and acetate in cultured cortical astrocytes: Changes induced by ammonia. J. Neurochem. 2016, 136, 329-338, doi:10.1111/jnc.13376. 